\title{
Prognostic Improvement of Acute Necrotizing Eosinophilic Myocarditis (ANEM) Through a Rapid Pathological Diagnosis and Appropriate Therapy
}

\author{
Akihiko Yonenaga, ${ }^{1}$ MD, Eriko Hasumi, ${ }^{1}$ MD, Katsuhito Fujiu, ${ }^{1}$ MD, Aya Ushiku, ${ }^{2}$ MD, \\ Masaru Hatano, ${ }^{1} \mathrm{MD}$, Jiro Ando, ${ }^{1} \mathrm{MD}$, Hiroyuki Morita, ${ }^{1} \mathrm{MD}$, \\ Masafumi Watanabe, ${ }^{1} \mathrm{MD}$ and Issei Komuro, ${ }^{1} \mathrm{MD}$
}

\begin{abstract}
Summary
We present the case of a patient with acute necrotizing eosinophilic myocarditis (ANEM) who rapidly recovered after receiving high-dose corticosteroid therapy. A previously healthy 29 -year-old woman presented to our hospital with abdominal pain, nausea, and fever that had lasted for two days. Her clinical condition progressively declined and she ultimately presented with cardiogenic shock due to fulminant heart failure and atrioventricular dissociation due to sinus bradycardia, which required inotropic and ventilatory support. Endomyocardial biopsy results were consistent with ANEM. High-dose corticosteroids were promptly initiated, and her cardiac function rapidly improved, with almost complete cardiac recovery one week later. She survived with completely normalized left ventricular systolic and diastolic function after high-dose corticosteroid therapy. The prompt and definite pathological diagnosis based on endomyocardial biopsy in the acute phase might have been instrumental in improving the outcome.
\end{abstract}

(Int Heart J 2018; 59: 641-646)

Key words: Eosinophil, Endomyocardial biopsy, Steroid therapy

$\mathrm{C}$ ardiac diseases associated with eosinophilia are categorized into 4 groups: systemic disease [hypereosinophilic syndrome (HES), eosinophilic granulomatosis with polyangiitis (EGP), and malignancies], drug allergy reactions, parasitic infections, and a fulminant form of hypersensitivity myocarditis called acute necrotizing eosinophilic myocarditis (ANEM). ${ }^{1}$ ANEM is rarely diagnosed while patients are alive because of its rapid and fatal progression within days to a week and its nonspecific clinical manifestations. Most cases are diagnosed when performing an autopsy, though it is frequently impossible to identify a definitive cause. ${ }^{2)}$ The mortality rate exceeds $50 \%$, and the average survival duration is $<4$ days. ${ }^{1}$ The main causes are arrhythmia and cardiogenic shock. We report the case of a 29-yearold woman presenting with mild blood peripheral eosinophilia and having unique echocardiographic images and who was pathologically diagnosed with ANEM on performing endomyocardial biopsy in the early stage. She had a good outcome because of her precise diagnosis and appropriate therapy. We present an approach for the prompt diagnosis of and appropriate therapeutic choice for ANEM based on clinical findings.

\section{Case Report}

A 29-year-old woman presented to our hospital complaining of abdominal pain, nausea, fever, and dyspnea that had lasted for two days. Transvaginal and abdominal ultrasound revealed no significant finding, whereas blood tests showed elevated levels of hepatic enzymes [Aspartate aminotransferase (AST): $153 \mathrm{U} / \mathrm{L}$, Alanine aminotransferase (ALT): $110 \mathrm{U} / \mathrm{L}]$. A computed tomography (CT) scan was performed, and showed that there was no abnormality in the peritoneal and pelvic cavity. Her abdominal pain resolved immediately after visiting the hospital and she then returned home. Two days later, she was referred to our cardiology outpatient department for the reevaluation of liver dysfunction and because of persistent chest discomfort. Blood tests revealed that her serum creatine kinase (CK) level had increased to $433 \mathrm{U} / \mathrm{L}$, while her CKMB level (CK-MB isoenzyme) was $39 \mathrm{U} / \mathrm{L}$, troponin T $0.9 \mathrm{ng} / \mathrm{mL}$, and BNP $450 \mathrm{pg} / \mathrm{mL}$. Her leukocyte count was $7100 / \mu \mathrm{L}$, predominantly showing neutrophils $(5133 / \mu \mathrm{L})$ and monocytes $(653 / \mu \mathrm{L})$, and she had a normal eosinophil count (362/ $/ \mu \mathrm{L}, 5.1 \%)$. Her C-reactive protein level was initially elevated at $0.94 \mathrm{mg} / \mathrm{dL}$ (Table). Cardiology consultation revealed moderate pericardial effusion on a CT scan, which was performed at the first

From the ${ }^{1}$ Department of Cardiovascular Medicine, The University of Tokyo Hospital, Tokyo, Japan and ${ }^{2}$ Department of Pathology, The University of Tokyo Hospital, Tokyo, Japan.

Address for correspondence: Eriko Hasumi, MD, Department of Cardiovascular Medicine, The University of Tokyo Hospital, 7-3-1 Hongo, Bunkyo-ku, Tokyo 113-8655, Japan. E-mail: ehasumi-circ@umin.ac.jp

Received for publication June 2, 2017. Revised and accepted August 9, 2017.

Released in advance online on J-STAGE April 6, 2018.

doi: 10.1536/ihj.17-308

All rights reserved by the International Heart Journal Association. 
visit. An echocardiogram showed significant concentric edematous thickening of the left ventricular (LV) wall and mild pericardial effusion. Because a provisional diagnosis of acute myocarditis was made, she was admitted to the coronary care unit under the care of the cardiology team for further evaluation. She had no upper respiratory tract infections in the preceding weeks, and was not exposed to animals and did not smoke.

Table. Laboratory Findings During the Patient's Clinical Course

\begin{tabular}{lrrrr}
\hline & $\begin{array}{c}\text { On } \\
\text { admission }\end{array}$ & $\begin{array}{c}\text { On } \\
\text { day 3 }\end{array}$ & $\begin{array}{c}\text { On day 4 } \\
\text { (after steroid } \\
\text { pulse therapy) }\end{array}$ & $\begin{array}{r}\text { At two } \\
\text { weeks }\end{array}$ \\
\hline WBC $(/ \mu \mathrm{L})$ & 7100 & 8900 & 7800 & 10700 \\
Eosinophil $(/ \mu \mathrm{L})$ & 362 & 774 & 0 & 161 \\
$\mathrm{RBC}\left(\times 10^{9} / \mu \mathrm{L}\right)$ & 4.82 & 3.88 & 3.43 & 4.36 \\
$\mathrm{Hb}(\mathrm{g} / \mathrm{dL})$ & 15.1 & 11.8 & 10.5 & 13.7 \\
$\mathrm{Ht}(\%)$ & 43.9 & 35.1 & 31.4 & 40.5 \\
$\mathrm{Platelets}\left(\times 10^{9} / \mu \mathrm{L}\right)$ & 29.9 & 20.9 & 23.2 & 33.3 \\
$\mathrm{CK}(\mathrm{U} / \mathrm{L})$ & 433 & 148 & 34 & 18 \\
$\mathrm{CK}-\mathrm{MB}(\mathrm{U} / \mathrm{L})$ & 39 & 14 & 5 & \\
$\mathrm{AST}(\mathrm{U} / \mathrm{L})$ & 66 & 26 & 9 & 15 \\
$\mathrm{ALT}(\mathrm{U} / \mathrm{L})$ & 102 & 46 & 25 & 46 \\
$\mathrm{LDH}(\mathrm{U} / \mathrm{L})$ & 322 & 297 & 198 & 192 \\
$\mathrm{BUN}(\mathrm{mg} / \mathrm{dL})$ & 19.5 & 9.8 & 15.5 & 13.4 \\
$\mathrm{Cr}(\mathrm{mg} / \mathrm{dL})$ & 0.84 & 0.46 & 0.45 & 0.66 \\
$\mathrm{CRP}(\mathrm{mg} / \mathrm{dL})$ & 0.94 & 3.17 & 1.15 & 0.01 \\
$\mathrm{BNP}(\mathrm{pg} / \mathrm{mL})$ & 450 & & 160.2 & 19.5 \\
IgE $(\mathrm{IU} / \mathrm{mL})$ & 330 & & & \\
ECP $(\mu \mathrm{g} / \mathrm{L})$ & 48.2 & & & \\
\hline
\end{tabular}

On admission, her blood pressure, pulse, and body temperature were $92 / 42 \mathrm{mmHg}, 62$ beats/minute, and $37.0^{\circ} \mathrm{C}$, respectively. Her blood oxygen saturation was $96 \%$ in room air. A cardiac examination showed no jugular venous distention, gallops, rubs, or murmurs.

Electrocardiography showed sinus rhythm, poor Rwave progression, and ST-segment elevation in leads V1 to V6 (Figure 1). X-rays showed no cardiomegaly or pulmonary edema. A 2-dimensional echocardiogram revealed moderate LV systolic dysfunction [ejection fraction (EF): $38 \%$ ] with global hypokinesis, whereas her LV cavity size was normal. It also revealed significant concentric edematous thickening of the LV wall (12 $\mathrm{mm}$ during diastole) and a moderate amount of pericardial effusion $(16.8 \mathrm{~mm}$ wide echo-free space posteriorly) without signs of tamponade. The right ventricle (RV) was moderately thickened with mild systolic dysfunction. Pulsed-wave Doppler imaging of mitral inflow demonstrated that the ratio of the E wave to the A wave was low at 1.39 (E wave: $50 \mathrm{~cm} / \mathrm{s}$, A wave: $36 \mathrm{~cm} / \mathrm{s}$ ) and that the deceleration time was prolonged (Dct: $238 \mathrm{~ms}$ ), which suggested that LV relaxation had deteriorated (Figure 2A). Several hours after arrival in the coronary care unit, persistent hypotension $(80 \mathrm{mmHg})$, oliguria, impaired mental function, and peripheral vasoconstriction associated with cold, clammy skin were observed. A diagnosis of cardiogenic shock was made. ${ }^{3)}$ Atrioventricular dissociation due to sinus bradycardia (HR: 50 beats/minute) and frequent premature ventricular contractions (PVCs) also occurred, and her chest pain and dyspnea worsened. She required vigorous inotropic and on admission

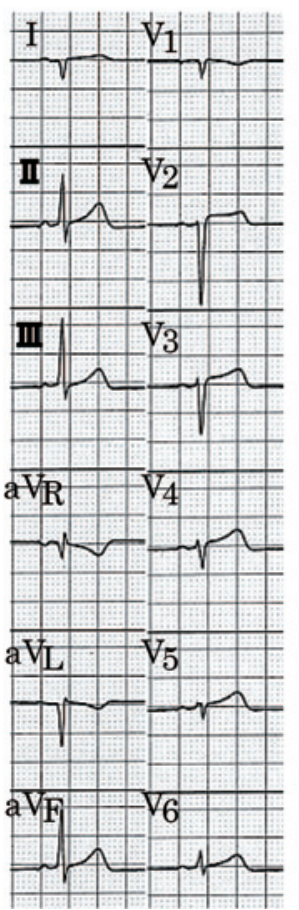

day 3

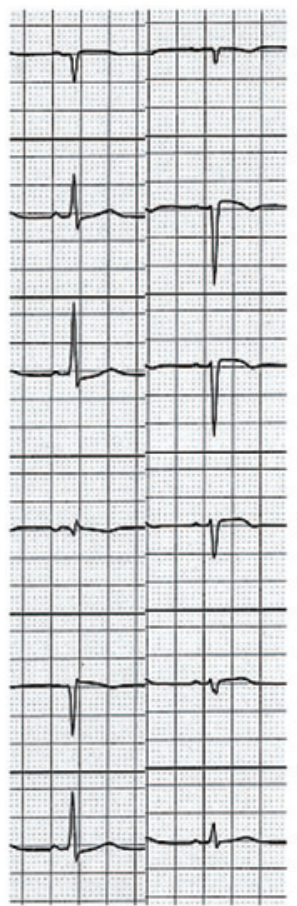

1 week

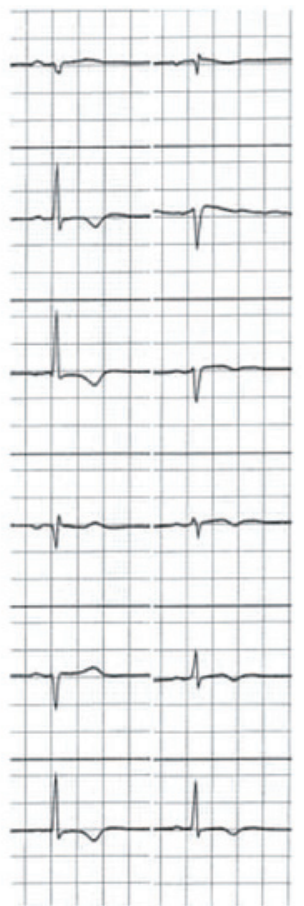

2 months

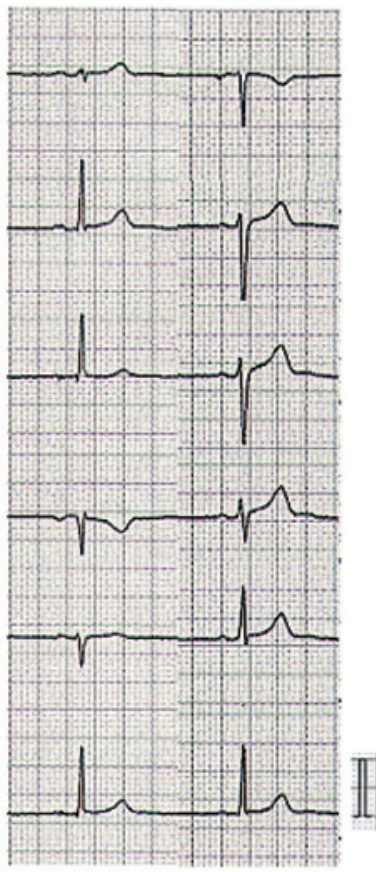

Figure 1. Time-course changes in ECG. Initial ECG showed global reduction of R-wave voltage with widespread ST-segment elevation. Regression of ST-segment elevation and repolarization in precordial leads were observed during the clinical course. 
On admission

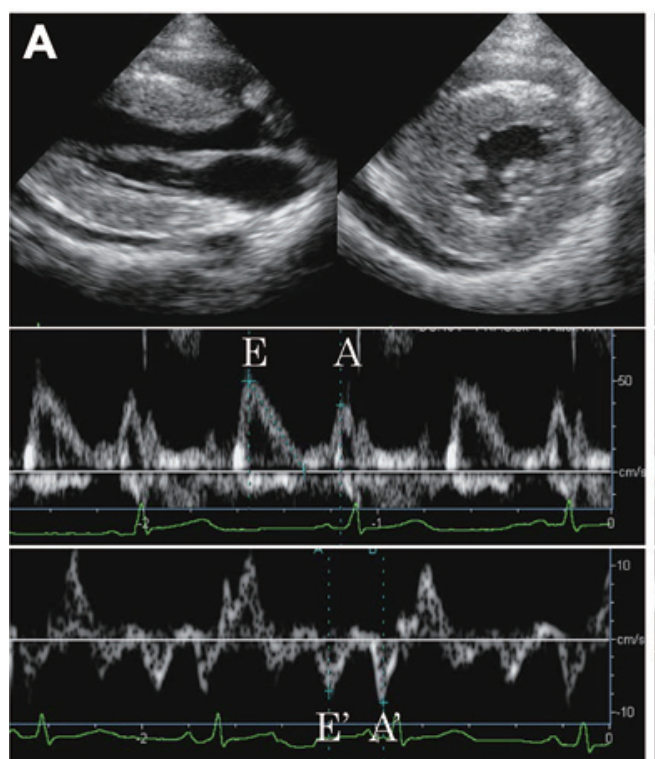

After steroid pulse therapy

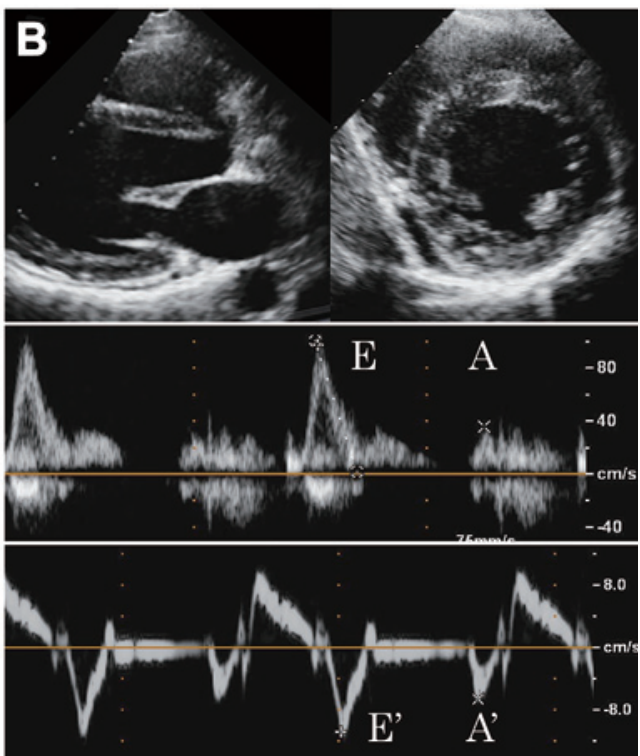

Figure 2. Echocardiographic findings. A: Two-dimensional echocardiography showed severe LV hypertrophy and global systolic dysfunction on admission. Transmitral flow velocity pattern: early diastolic filling wave (E-wave) was decreased $(50 \mathrm{~cm} / \mathrm{s})$, and atrial filling wave (A-wave) was increased $(36 \mathrm{~cm} / \mathrm{s})$. The A-wave duration time and E-wave deceleration time (DT) were prolonged $(238 \mathrm{~ms})$. Peak early diastolic velocity of the mitral annulus (E'): E' was decreased. These findings indicated impaired LV relaxation. B: After steroid-pulse therapy, echocardiography showed a marked reduction in left ventricular thickness and improvement of both LV systolic function and diastolic function.

mechanical ventilatory support. Administration of dopamine injection resulted in increases in urine flow and blood pressure. Lung congestion due to heart failure improved with vigorous inotropic and ventilatory support.

Due to a high fever of $39^{\circ} \mathrm{C}$ on day 2, we started high-dose intravenous immunoglobulin therapy $(0.1 \mathrm{~g} / \mathrm{kg} /$ day) to suppress the acute fulminant myocarditis. On day 3 , her vital signs became stable and her LV systolic function improved. However, an echocardiogram showed a thickened LV wall (interventricular septum: $16 \mathrm{~mm}$ ) and worsened diastolic dysfunction ( $E$ wave: $0.74 \mathrm{~m} / \mathrm{s}$, A wave: $0.54 \mathrm{~m} / \mathrm{s}$, E/A: 1.37 , Dct: $268 \mathrm{~ms})$. Blood tests indicated a high eosinophil count $(774 / \mu \mathrm{L}, 6.5 \%)$. Eosinophilic myocarditis was suspected, and cardiac catheterization, including endomyocardial biopsy, was performed. Cardiac angiography showed a normal coronary artery and deterioration of LV systolic function (EF: 45\%). The LV end-diastolic pressure was high $(22 \mathrm{mmHg})$ and the cardiac index (thermodilution) was $3.02 \mathrm{~L} /$ minute $/ \mathrm{m}^{2}$. An $\mathrm{LV}$ endomyocardial biopsy was performed, and the myocardial specimens were stained with hematoxylin-eosin, elastica van Gieson (EVG), and Giemsa stains. A pathologic evaluation demonstrated that inflammatory cells with extensive necrosis had infiltrated into the myocardium and that most cells were eosinophils (Figure 3B). Eosinophils in the myocardium were often degranulated at high magnification ( $\times 600$ at original magnification) (Figure 3C). Mild fibrosis was also detected on EVG staining (Figure 3 A). Due to these findings, a definite pathological diagnosis of eosinophilic myocarditis was made on the same day. An elevated serum immunoglobulin E level of 330 IU/L and eosinophilic cationic protein level (ECP) of $48.2 \mu \mathrm{g} / \mathrm{L}$ also supported the diagnosis. During the diagnostic investigation of the etiology, additional laboratory analyses including repeated blood cultures, viral antibodies, parasite-specific antibodies, blood tumor series, and autoimmune series - provided no evidence of hematogenous infections or autoimmune diseases.

The patient was diagnosed with ANEM in the pathological analysis and was immediately started on 3 intravenous boluses of methylprednisolone (1000 mg/day). On the basis of the potential risk of thromboembolism due to potential endocardial damage, adjuvant anticoagulation therapy with low-molecular weight heparin was administered. Low-molecular weight heparin (10,000-15,000 units/24 hours) was continued during high-dose steroid therapy (days 2-11). After steroid pulse therapy, LV wall thickness and diastolic function rapidly improved to within the normal range (Figure 2). The peripheral eosinophil count promptly decreased and the BNP level also decreased (Table), accompanied by a regression of STsegment elevation and repolarization in precordial leads (Figure 1). On day 6, she was extubated and successfully weaned off inotropic agents and received $30 \mathrm{mg}$ prednisone PO daily that was slowly tapered. On day 10, a betablocker and an angiotensin II receptor blocker were started for the prevention of myocardial remodeling. Follow-up LV endomyocardial biopsy was performed 45 days after admission. Histological analysis of the biopsy showed an absence of eosinophilic infiltration in the myocardial interstitium (Figure 4). Two months after admission, the patient was discharged from the hospital with in- 

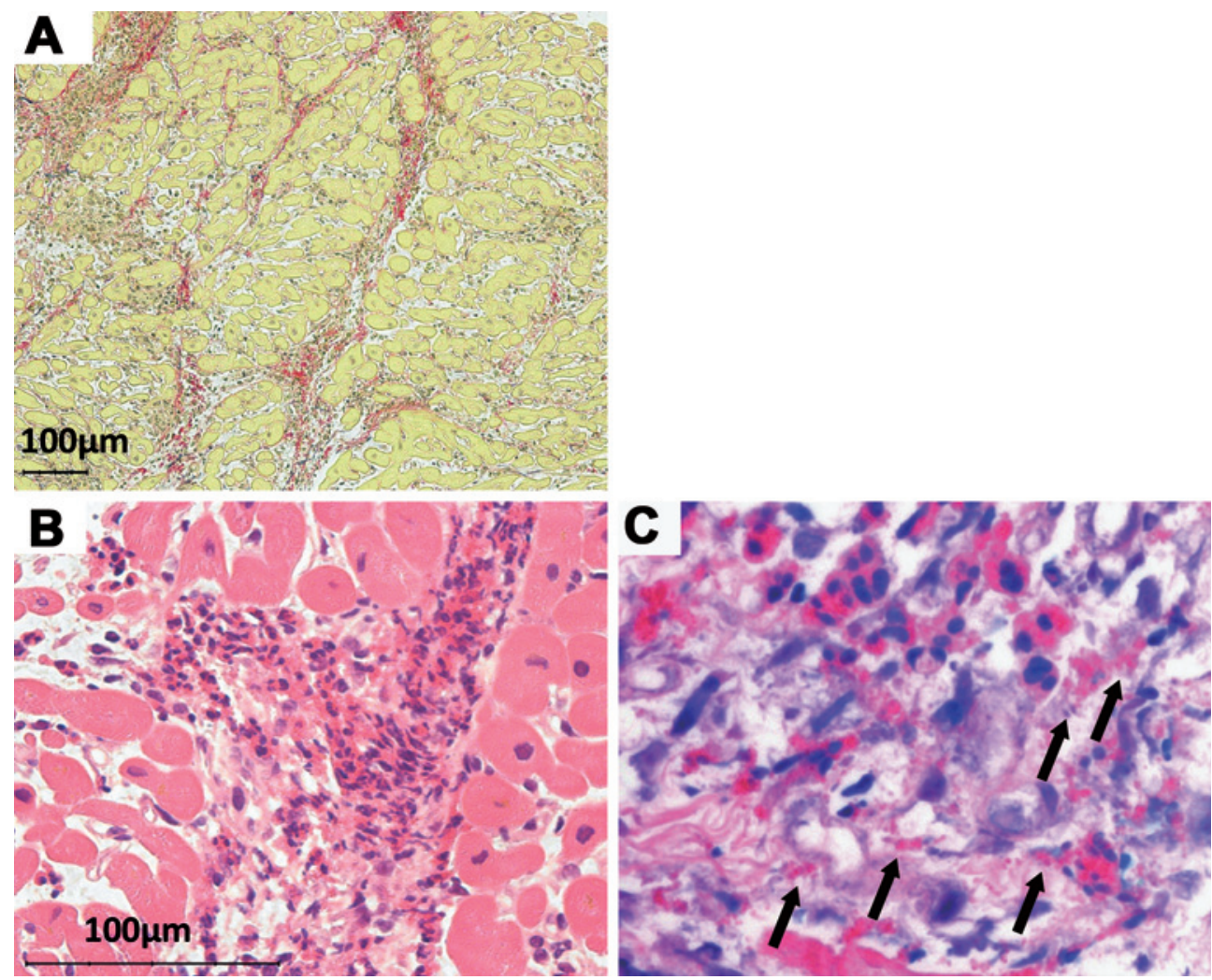

Figure 3. Histological findings on endomyocardial biopsy. A: Mild myocardial interstitial fibrosis was detected (EVG stain). B: Dead myocytes and a diffuse eosinophil-rich inflammatory infiltrate with interstitial edema (hematoxylin-eosin (HE) stain). C: Some infiltrated eosinophils were degranulated (Giemsa stain, $\times 600$ ).
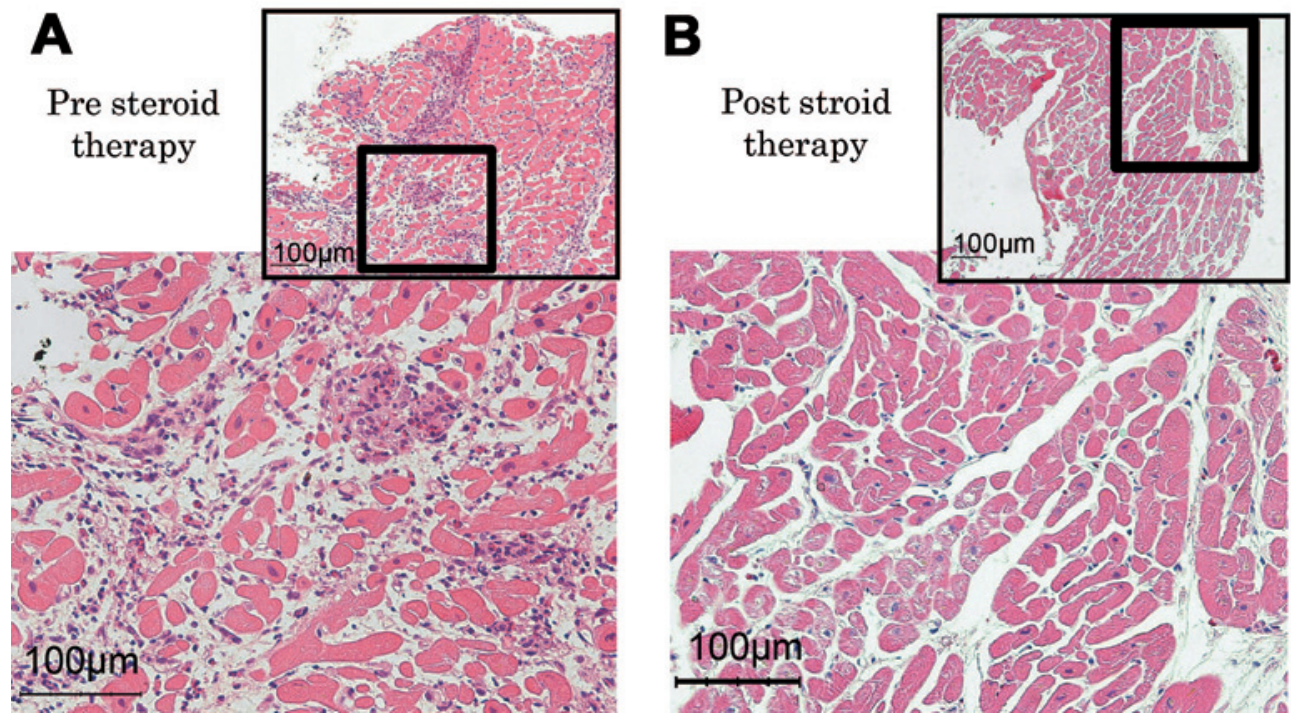

Figure 4. Follow-up left ventricular biopsy one and a half months after admission. Biopsy revealed a marked reduction of the eosinophilic infiltrate and the absence of active myocyte necrosis (HE stain).

structions to take $18 \mathrm{mg}$ prednisolone/day. She demonstrated a remarkable decrease in BNP levels after therapy, from $449.9 \mathrm{pg} / \mathrm{mL}$ initially to $16.9 \mathrm{pg} / \mathrm{mL}$ on discharge. The dose of corticosteroids was gradually tapered down for one and a half years. During the follow-up period, she maintained normal systolic LV function, with a normal eosinophil count (350-500 $\mu / \mathrm{L})$ (Figure 5). Although prednisolone and the angiotensin II receptor blocker were dis- 

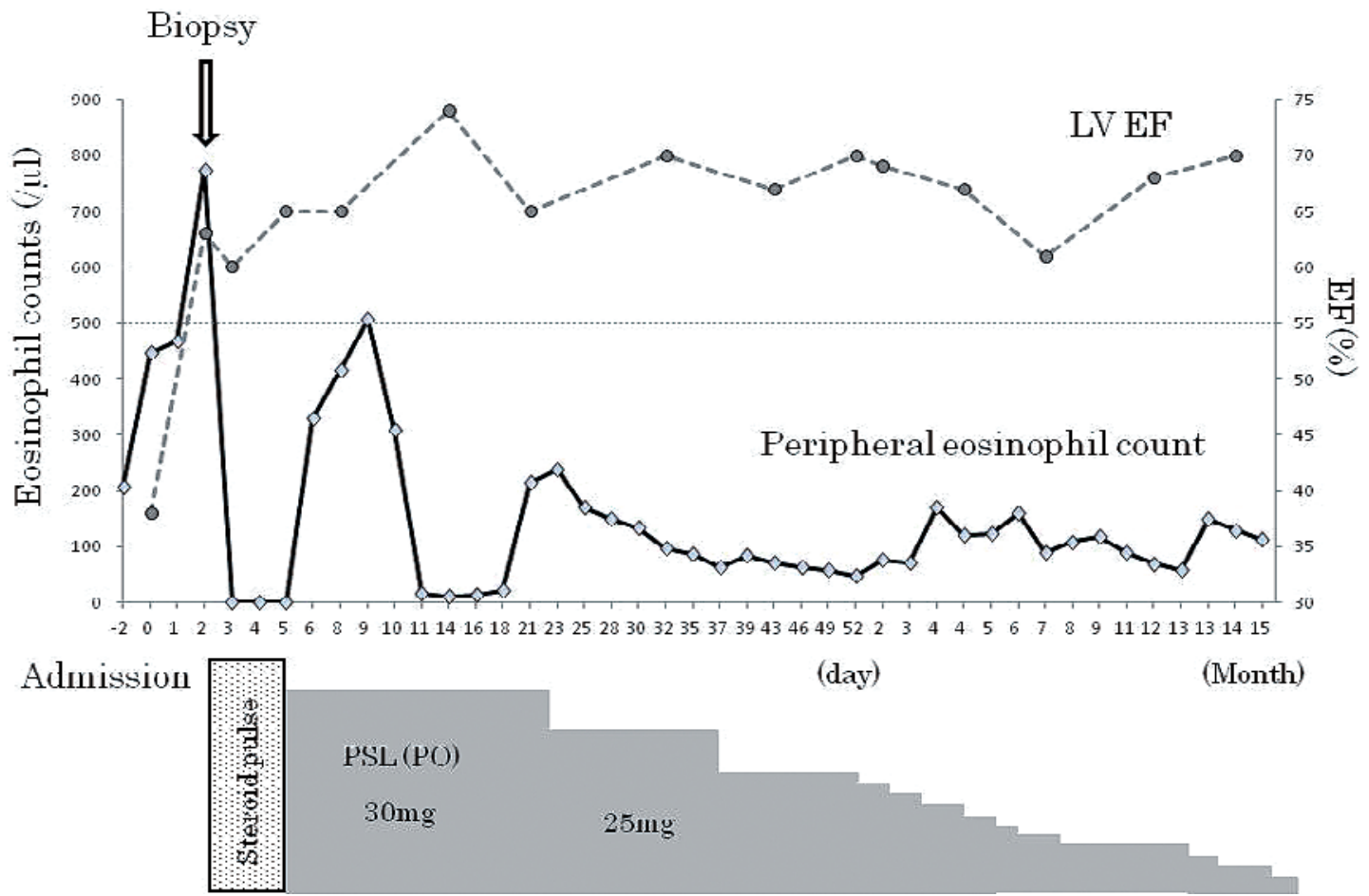

Figure 5. Time course of eosinophil count and left ventricular (LV) ejection function (EF) during follow-up period.

continued, she reported no symptoms of heart failure and echocardiography showed normal LV systolic function. Since she is planning on becoming pregnant, the betablocker is scheduled to be discontinued.

\section{Discussion}

Eosinophilic myocarditis (EM) has been identified in $0.5 \%$ of cases in an unselected autopsy series ${ }^{4)}$ and in $0.1 \%$ of cases in a cohort of patients biopsied for suspected myocarditis. ${ }^{5}$ ANEM is a rare and the most severe form of EM characterized by eosinophilic infiltration and extensive myocyte necrosis that present with fulminate heart failure and a high mortality rate. ${ }^{6}$ EM may occur secondary to a systemic disease, such as malignancy, HES, EGP, and parasite infection. Many drugs, including clozapine, macrolide antibiotics, penicillin derivates, methyldopa, and some anti-seizure drugs, have been suspected as possible etiologic agents. ${ }^{4,7,8}$ Some anti-inflammatory drugs, such as diclofenac, indomethacin, phenylbutazone, and oxyphenbutazone, are also capable of causing $\mathrm{EM}^{4)}$. However, the etiology of ANEM was unclear, and some recent reports have presented cases of drug-induced ANEM. ${ }^{6,9-13)}$

Clinical manifestation of ANEM may include nonspecific flu-like symptoms followed by rapid progression to severe hemodynamic deterioration with severe heart failure, cardiogenic shock, and potentially fatal arrhythmias. ST-segment elevation in ECG and elevated blood levels of cardiac enzymes are often seen. Blood eosinophilia is present in most cases, but it can be mild. ${ }^{14)}$ Characteristic echocardiographic findings of ANEM were use- ful for our prompt diagnosis. Echocardiography typically shows a normal chamber size (reflecting the sudden onset), increased wall thickness, and severe, biventricular diffuse systolic dysfunction. Pericardial effusion is seen in $75 \%$ of cases. ${ }^{15)}$ Endomyocardial biopsy is considered the gold standard for correctly diagnosing ANEM. Thus, a biopsy should be immediately performed if ANEM is suspected on the basis of other examinations. A histological examination shows diffuse inflammation in the myocardium, including the infiltration of a prominent eosinophilic component and extensive myocyte necrosis.

Given the absence of randomized control trials to guide ANEM therapy, mechanical circulatory support, immunosuppression, and standard heart-failure medical therapies are the basis of ANEM treatment. ${ }^{1,14,16,17)}$ In EM, the myocardium is damaged by proteins derived from eosinophils, such as ECP, major basic protein (MBP), eosinophil-derived neurotoxin (EDN), and eosinophil peroxidase (EPO). The aim of corticosteroid therapy is to stop toxic granule release and the subsequent immunological destruction of the myocardium. Consequently, initial therapy generally involves high-dose steroids. Nevertheless, a general recommendation for the dosage of corticosteroids and the duration of treatment remains unclear.

In this case, medical history and screening tests eliminated medication side effects, allergic responses, infection, malignancy, and connective tissue disorders as the cause of ANEM. On the basis of endomyocardial biopsy results, we decided to treat our patient with 3 intravenous boluses of methylprednisolone ( $1 \mathrm{~g} /$ day $)$ and immunoglobulin $(0.1 \mathrm{~g} / \mathrm{kg} /$ day $)$ for 4 days followed by $30 \mathrm{mg} /$ day oral prednisone $(0.6 \mathrm{mg} / \mathrm{kg} /$ day $)$ at a tapered dose for two 
weeks. We performed endomyocardial biopsy one and a half months after administering corticosteroid therapy. The histopathological findings showed almost complete resolution of the eosinophilic infiltration and improvement of the fibrosis. Therefore, we gradually tapered the steroid dose for 1 year based on the echocardiographic assessment of cardiac function as well as eosinophil count. With the therapeutic regimen outlined above, the high-dose corticosteroids that we administered in the early stages may have been instrumental in preventing progression to the intermediate necrotic and fibrotic stage of AENM and the complete recovery with normal systolic function.

Recent case reports have demonstrated that patients with drug-induced ANEM were successfully treated with immediate withdrawal of the offending drug and immunosuppressant therapy. ${ }^{6,9,10,18)}$ However, no study has reported that a patient with ANEM of unknown etiology can be successfully diagnosed, in whom only immunosuppressive therapy results in a full recovery of LV function. Therefore, knowledge about the clinical course of ANEM and a prompt decision to perform endomyocardial biopsy in patients with acute deterioration of heart function of unknown origin is recommended to differentially diagnose ANEM and save the life of the patient.

\section{Conclusion}

ANEM is a medical emergency that is usually fatal, and the condition is difficult to diagnose before the patient dies. We had a strong clinical suspicion of ANEM based on the unique echocardiographic findings, and were able to perform a prompt endomyocardial biopsy and make a correct diagnosis. Furthermore, the immediate administration of high-dose corticosteroids led to dramatic improvements without mechanical support in our patient. We have reported the case of a patient with idiopathic ANEM who presented with cardiogenic shock, was diagnosed by performing endomyocardial biopsy at an early stage, and showed complete recovery without sequelae. Making a precise pathological diagnosis by performing endocardial biopsy and administering appropriate steroids are needed to improve the prognosis of patients with ANEM.

\section{Disclosures}

Conflicts of interest: None.

\section{References}

1. Sabatine MS, Poh KK, Mega JL, Shepard JA, Stone JR, Frosch
MP. Case records of the Massachusetts General Hospital. Case 36-2007. A 31-year-old woman with rash, fever, and hypotension. N Engl J Med 2007; 357: 2167-78.

2. Herzog CA, Snover DC, Staley NA. Acute necrotising eosinophilic myocarditis. Br Heart J 1984; 52: 343-8.

3. Swan HJ, Forrester JS, Diamond G, Chatterjee K, Parmley WW. Hemodynamic spectrum of myocardial infarction and cardiogenic shock. A conceptual model. Circulation 1972; 45: 1097110.

4. Al Ali AM, Straatman LP, Allard MF, Ignaszewski AP. Eosinophilic myocarditis: case series and review of literature. Can J Cardiol 2006; 22: 1233-7. (Review)

5. Maisch B, Pankuweit S. Current treatment options in (peri)myocarditis and inflammatory cardiomyopathy. Herz 2012; 37: 64456. (Review)

6. Byard RW. Farming deaths - an ongoing problem. Forensic Sci Med Pathol 2017; 13: 1-3.

7. Huston B, Froloff V, Mills K, McGee M. Death due to eosinophilic necrotizing myocarditis despite steroid treatment. Am J Forensic Med Pathol 2013; 34: 95-7.

8. Galiuto L, Enriquez-Sarano M, Reeder GS, et al. Eosinophilic myocarditis manifesting as myocardial infarction: early diagnosis and successful treatment. Mayo Clin Proc 1997; 72: 603-10. (Review)

9. Howell E, Paivanas N, Stern J, Vidula H. Treatment of acute necrotizing eosinophilic myocarditis with immunosuppression and mechanical circulatory support. Circ Heart Fail 2016; 9: e003665.

10. Jeremic I, Vujasinovic-Stupar N, Terzic T, Damjanov N, Nikolic M, Bonaci-Nikolic B. Fatal sulfasalazine-induced eosinophilic myocarditis in a patient with periodic fever syndrome. Med Princ Pract 2015; 24: 195-7.

11. Allen SF, Godley RW, Evron JM, Heider A, Nicklas JM, Thomas MP. Acute necrotizing eosinophilic myocarditis in a patient taking Garcinia cambogia extract successfully treated with highdose corticosteroids. Can J Cardiol 2014; 30: 1732.e13-5.

12. Adamson R, Yazici Y, Katz ES, Greisman SG, Steiger D. Fatal acute necrotizing eosinophilic myocarditis temporally related to use of adalimumab in a patient with relapsing polychondritis. J Clin Rheumatol 2013; 19: 386-9.

13. Kawabori M, Kurihara C, Miller Y, et al. Total artificial heart implantation for biventricular failure due to eosinophilic myocarditis. J Artif Organs 2017; 20: 266-9.

14. Fozing T, Zouri N, Tost A, et al. Management of a patient with eosinophilic myocarditis and normal peripheral eosinophil count: case report and literature review. Circ Heart Fail 2014; 7: 692-4. (Review)

15. Kazama R, Okura Y, Hoyano M, et al. Therapeutic role of pericardiocentesis for acute necrotizing eosinophilic myocarditis with cardiac tamponade. Mayo Clin Proc 2003; 78: 901-7.

16. Cooper LT, Zehr KJ. Biventricular assist device placement and immunosuppression as therapy for necrotizing eosinophilic myocarditis. Nat Clin Pract Cardiovasc Med 2005; 2: 544-8.

17. Amao R, Imamura T, Sawada Y, et al. Experiences with aggressive cardiac rehabilitation in pediatric patients receiving mechanical circulatory supports. Int Heart J 2016; 57: 769-72.

18. Moriwaki K, Dohi K, Omori T, et al. A survival case of fulminant right-side dominant eosinophilic myocarditis. Int Heart $\mathrm{J}$ 2017; 58: 459-62. 